\title{
Galactose functionalized diketopyrrolopyrrole as NIR fluorescent probes for lectin detection and HepG2 cell targeting based on aggregation-induced emission mechanism
}

\author{
Yandi Hang ${ }^{1,2 \dagger}$, Xiaolei Cai ${ }^{2,3 \dagger}$, Jian Wang ${ }^{1}$, Tao Jiang ${ }^{1}$, Jianli Hua ${ }^{1 *} \&$ Bin Liu $^{2 *}$ \\ ${ }^{1}$ Key Laboratory for Advanced Materials and Joint International Research Laboratory of Precision Chemistry and Molecular Engineering, \\ Feringa Nobel Prize Scientist Joint Research Center, School of Chemistry and Molecular Engineering, East China University of Science \& \\ Technolog, Shanghai 200237, China; \\ ${ }^{2}$ Department of Chemical and Biomolecular Engineering, National University of Singapore, Singapore 117585, Singapore; \\ ${ }^{3}$ NUS Graduate School for Integrative Sciences and Engineering, National University of Singapore, Singapore 117456, Singapore
}

Received March 10, 2018; accepted April 16, 2018; published online June 19, 2018

\begin{abstract}
Since the elucidation that sugar-lectin interactions contribute to the understanding of "Glycomics", how to construct glycosensors with rapid response, excellent sensitivity and selectivity is of intense research interest. Herein, we report the design of three NIR emissive glyco-probes based on diketopyrrolopyrrole (DPPs) conjugated with two (DPPG), four (DPPF-G) and six (DPPS-G) galactose groups. All three molecules could probe lectins with excellent sensitivity and selectivity. The increase of glyco-DPP emission in NIR region upon interaction with lectin is due to the aggregates formation induced by sugar-lectin interactions, which have been verified by dynamic light scattering (DLS) and scanning electronic microscope (SEM) analysis. Due to the multiple glyco-ligands on DPPS-G, it has been successfully used to stain HepG2 cells through interactions between galactose and asialogly-coprotein (ASGP-R), which are overexpressed on the surface of HepG2 cells.
\end{abstract}

NIR emissive, glyco-probes, diketopyrrolopyrrole, sugar-lectin interactions

Citation: Hang Y, Cai X, Wang J, Jiang T, Hua J, Liu B. Galactose functionalized diketopyrrolopyrrole as NIR fluorescent probes for lectin detection and HepG2 cell targeting based on aggregation-induced emission mechanism. Sci China Chem, 2018, 61: 898-908, https://doi.org/10.1007/s11426-0189259-3

\section{Introduction}

Carbohydrate-mediated biological interactions play a crucial role in different cellular events $[1,2]$. Specific intercellular recognitions between carbohydrate and protein receptors (e.g., lectins) are found on cell surfaces [3]. The elucidation of these interactions may contribute to the understanding of the "Glycomics" and facilitate early-state disease diagnosis, as well as sugar-based drug and vaccine development [4]. Galectins and the asialoglycoprotein receptors (ASGPr) are

$\dagger$ These authors contributed equally to this work.

*Corresponding authors (email: jlhua@ecust.edu.cn; cheliub@nus.edu.sg) galactoside-recognition lectins encoded by the human genome. While these lectins play a key role in maintaining normal cellular functions, furthermore, recent investigations demonstrated that some human fatal diseases (such as cardiopathy, inflammation, and cancer) are associated with them $[5,6]$. The currently established methods such as western blotting and immune-cytochemistry techniques generally require complex operation [7]. Synthetic glycosensors have been developed and demonstrated to be a rapid, simple, sensitive, and selective tool for investigating carbohydrate-based biological events.

Recently, a number of optical probes for lectin detection have been reported [8-10]. Conventional dyes that possess 
planar and well-conjugated structures usually work in fluorescence-quenching mode when they are dispersed in aqueous media or upon interaction with biological analytes, which results in negative effects on practical applications. Since the intriguing discovery of the aggregation-induced emission (AIE) by Tang et al. [11], it has received intense research interest as it is opposite to aggregation-caused quenching mechanism. Luminogens with AIE characteristics can fluoresce strongly in the aggregate state, which opens a new avenue towards efficient solid-state light emitters [12,13], bioprobes [14-18], and chemosensors [19-22]. However, the current AIE systems are mainly focused on silole, tetraphenylethene (TPE) and cyanostilbene derivatives, which show short-wavelength fluorescence in the range of 400-600 nm.

Diketopyrrolopyrrole (DPP) and their derivatives have attracted considerable research interests over the last few decades due to their relatively simple synthesis, intense color and excellent photo-stability. Currently, DPPs have been extensively applied in construction of materials for twophoton absorption [23,24], fluorescent probes [25-27] and imaging [28,29]. DPP derivatives functionalized with electron donor groups usually exhibit red to near-infrared (NIR) emission and large Stokes shifts that are advantageous in biological applications [30-33].

Considering the polymeric feature of lectins that renders the formation of sugar-lectin complexes with high avidities [34], to evaluate the effect of the number of sugar groups on the probe performance, we developed three glyco-DPPs with two (DPPG), four (DPPF-G) and six (DPPS-G) sugar groups, respectively (Figure 1). The increasing number of sugars can improve both water solubility and binding efficiency. Furthermore, galactose is chosen to functionalize DPP to target HepG2 cells with overexpressed galactose receptor asialogly-coprotein (ASGP-R) on their surface, which has been suggested to evolve as a new class of biomarker for liver cancer $[35,36]$.

\section{Experimental}

\subsection{General experimental section}

$N, N$-dimethylformamide (DMF) was refluxed with calcium hydride and distilled before use. Tetrahydrofuran (THF) was pre-dried over $4 \AA$ molecular sieves and distilled under an argon atmosphere from sodium benzophenone ketyl immediately before use. 4,4'-((4-Bromophenyl)azanediyl )diphenol (compound 1) [37], 3,6-bis(4-bromophenyl)-2,5dihexyl-2,5-dihydropyrrolo[3,4-c]pyrrole-1,4-dione (compound 4) [38], 2,5-bis(6-bromohexyl)-3,6-bis (4-bromophenyl)-2,5-dihydropyrrolo[3,4-c]pyrrole-1,4-dione (compound 5) [39], and galactose alkyne [40] were prepared according to previous literature protocols. All other reagents and pro-

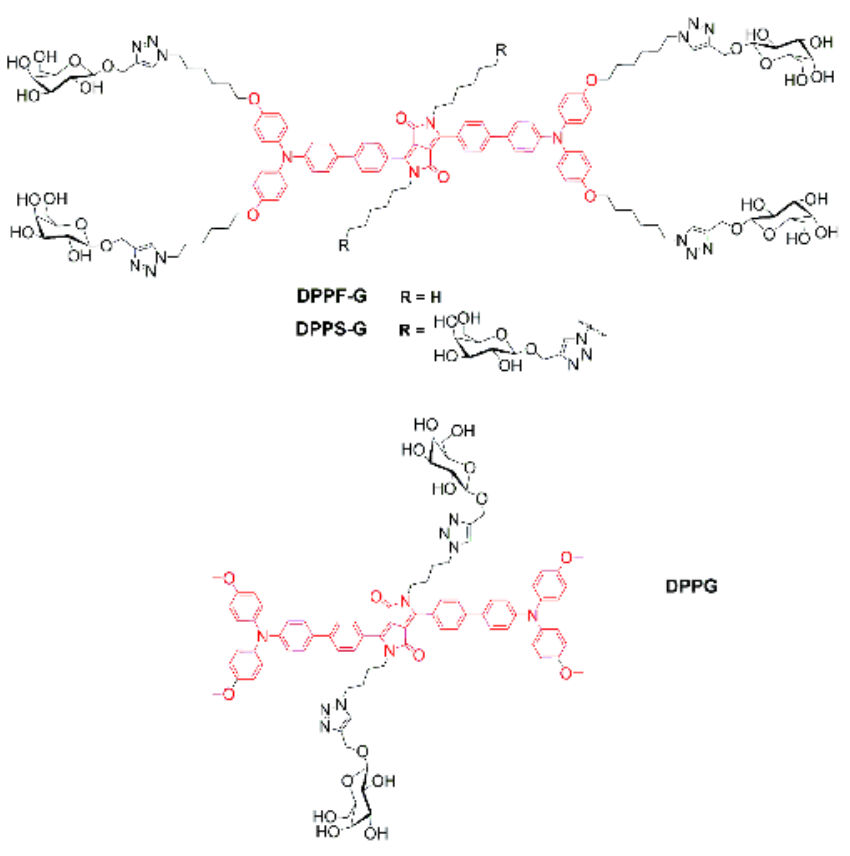

Figure 1 Structures of glyco-DPPs (color online).

teins were purchased from Sigma-Aldrich (USA) and used as received. The solutions for analytical studies were prepared with deionized water treated with a Milli-Q System (Billerica, USA).

${ }^{1} \mathrm{H}$ and ${ }^{13} \mathrm{C}$ NMR spectra were recorded on a Bruker AM $400 \mathrm{MHz}$ spectrometer with tetramethyl silane (TMS) as the internal reference (Germany). Electrospray ionization and time-of-flight analyzer (ESI-TOF) mass spectra were recorded with a Waters Micromass LCT mass spectrometer (USA). Matrix assisted laser desorption ionization and timeof-flight analyzer (MALDI-TOF) were recorded with an Applied Biosystems 4700 Proteomics Analyzer.

\subsubsection{Synthesis of 4-bromo-N,N-bis(4-((6-bromohexyl) oxy)phenyl)aniline (2)}

A mixture of $1(1.0 \mathrm{~g}, 2.81 \mathrm{mmol})$ and aqueous potassium carbonate $(2.33 \mathrm{~g}, 16.84 \mathrm{mmol})$ was dissolved in $20 \mathrm{~mL}$ acetone under argon atmosphere. Then 1,6-dibromohexane (2.6 $\mathrm{mL}, 16.84 \mathrm{mmol})$ was added dropwise to the reaction solution and stirred at $80^{\circ} \mathrm{C}$ for $12 \mathrm{~h}$. After cooling to room temperature, the mixture was filtered and washed with acetone. After removal of the filtrate solvent, the crude product was purified by column chromatography on silica gel (eluent: dichloromethane/petroleum ether $(1: 4, v / v)$ to obtain 2 (1.6 g, 83.5\% yield) as colorless liquid. ${ }^{1} \mathrm{H}$ NMR (400 MHz, $\mathrm{CDCl}_{3}$ ), $\delta$ (ppm): 7.23 (d, $\left.J=8.5 \mathrm{~Hz}, 2 \mathrm{H}\right), 7.01$ (d, $J=7.3 \mathrm{~Hz}, 4 \mathrm{H}), 6.80(\mathrm{~d}, J=8.8 \mathrm{~Hz}, 6 \mathrm{H}), 3.93$ (t, $J=5.8 \mathrm{~Hz}$, 4H), 3.43 (t, $J=6.8 \mathrm{~Hz}, 4 \mathrm{H}), 1.90$ (p, J=6.9 Hz, 4H), 1.79 (p, $J=6.5 \mathrm{~Hz}, 4 \mathrm{H}), 1.55-1.45$ (m, 8H). ${ }^{13} \mathrm{C}$ NMR $(100 \mathrm{MHz}$, $\left.\mathrm{CDCl}_{3}\right), \delta(\mathrm{ppm}): 158.15,155.53,147.96,140.45,133.39$, $131.75,127.69,126.57,121.94,115.34,114.75,112.27$, 
67.97, 33.85, 32.70, 29.17, 27.95, 25.35. LRMS (ESI, $m / z$ ): $[\mathrm{M}+\mathrm{H}]^{+}$calcd. for $\mathrm{C}_{30} \mathrm{H}_{37}{ }^{81} \mathrm{Br}_{2}{ }^{79} \mathrm{BrNO}_{2}{ }^{+}$684.0333, found 684.0386 .

\subsubsection{Synthesis of (4-(bis(4-((6-bromohexyl)oxy)phenyl) amino)phenyl)boronic acid (3)}

A solution of $2(1.36 \mathrm{~g}, 2.0 \mathrm{mmol})$ in $20 \mathrm{~mL}$ THF was stirred at $-78{ }^{\circ} \mathrm{C}$ for $0.5 \mathrm{~h}$ under argon atmosphere. Then $n$-BuLi in $n$-hexane solution $(2.5 \mathrm{M}, 1.6 \mathrm{~mL})$ was added dropwise to the solution. After stirred at for another $1 \mathrm{~h}$, triisopropyl borate $(0.6 \mathrm{~mL}, 2.4 \mathrm{mmol})$ was added to the reaction mixture. The mixture was stirred at $-78^{\circ} \mathrm{C}$ for $2 \mathrm{~h}$, then wormed to room temperature for another $2 \mathrm{~h}$. After completion of the reaction, the mixture was adjusted to weak acidic with hydrochloric acid (1 M), then adjusted to neutral with a saturated solution of potassium carbonate. The solvent was removed off to give crude product $(0.8 \mathrm{~g}, 62.0 \%)$ as yellowish liquid. This crude product was used directly for the next step without further purification.

2.1.3 Synthesis of 3,6-bis(4'-(bis(4-((6-bromohexyl) oxy) phenyl)amino)-[1,1'-bihnyl]-4-yl)-2,5-dihexyl-2,5-dihydropyrrolo[3,4-c]pyrrole-1,4-dione (6)

A mixture of 4 (307 mg, $0.5 \mathrm{mmol}), 3(1.29 \mathrm{~g}, 2.0 \mathrm{mmol})$, and $\mathrm{Pd}\left(\mathrm{PPh}_{3}\right)_{4}(10.5 \mathrm{mg}, 0.02 \mathrm{mmol})$ was dissolved in $15 \mathrm{~mL}$ THF under argon atmosphere. Aqueous potassium carbonate solution $(2 \mathrm{M}, 5 \mathrm{~mL})$ was added to the reaction solution and stirred at $60^{\circ} \mathrm{C}$ for $12 \mathrm{~h}$. After cooling to room temperature, the reaction mixture was extracted by dichloromethane $(3 \times 15 \mathrm{~mL})$. The combined organic layer was washed with water and dried over $\mathrm{Na}_{2} \mathrm{SO}_{4}$. After removal of the solvent, the crude product was purified by column chromatography on silica gel (eluent: dichloromethane/petroleum ether (3:1, $v / v)$ to obtain 4 (338 mg, 41.3\% yield) as a red solid. ${ }^{1} \mathrm{H}$ NMR (400 MHz, $\left.\mathrm{CDCl}_{3}\right), \delta(\mathrm{ppm}): 7.89(\mathrm{~d}, J=8.2 \mathrm{~Hz}, 4 \mathrm{H}), 7.70(\mathrm{~d}$, $J=8.2 \mathrm{~Hz}, 4 \mathrm{H}), 7.47$ (d, $J=8.5 \mathrm{~Hz}, 4 \mathrm{H}), 7.09$ (d, $J=8.7 \mathrm{~Hz}$, $8 \mathrm{H}), 6.99$ (d, $J=8.4 \mathrm{~Hz}, 4 \mathrm{H}), 6.84(\mathrm{~d}, J=8.8 \mathrm{~Hz}, 8 \mathrm{H}), 3.95$ (t, $J=6.3 \mathrm{~Hz}, 8 \mathrm{H}), 3.86-3.74(\mathrm{t}, J=8.0 \mathrm{~Hz}, 4 \mathrm{H}), 3.43$ (t, $J=$ $6.8 \mathrm{~Hz}, 8 \mathrm{H}), 1.91$ (p, $J=6.6 \mathrm{~Hz}, 8 \mathrm{H}), 1.80$ (p, $J=6.2,5.8 \mathrm{~Hz}$, $8 \mathrm{H}), 1.57-1.47(\mathrm{~m}, 16 \mathrm{H}), 1.25-1.27(\mathrm{~m}, 16 \mathrm{H}), 0.83(\mathrm{t}, J=$ $5.3 \mathrm{~Hz}, 2 \mathrm{H}) .{ }^{13} \mathrm{C}$ NMR $\left(100 \mathrm{MHz}, \mathrm{CDCl}_{3}\right), \delta(\mathrm{ppm}): 162.91$, $155.61,148.00,143.39,140.36,131.13,129.20,127.53$, $126.93,126.49,126.05,120.07,115.29,109.66,67.94$, $42.15,33.86,32.68,31.24,29.46,29.15,27.93,26.44,25.33$, 22.49, 13.99. LRMS (ESI, $m / z):[\mathrm{M}+\mathrm{H}]^{+}$calcd. for $\mathrm{C}_{90} \mathrm{H}_{107}$ ${ }^{81} \mathrm{Br}_{2}{ }^{79} \mathrm{Br}_{2} \mathrm{~N}_{4} \mathrm{O}_{6}{ }^{+} 1659.4883$, found 1659.4557 .

2.1.4 Synthesis of 3,6-bis(4'-(bis(4-((6-bromohexyl) oxy) phenyl)amino)-[1,1'-bihnyl]-4-yl)-2,5-bis(6-bromohexyl)2,5-dihydropyrrolo[3,4-c]pyrrole-1,4-dione (7)

The synthesis was performed following the same procedure of 6 starting with 5 (386 mg, $0.5 \mathrm{mmol})$ and 3 (1.29 g, $2.0 \mathrm{mmol})$. The crude product was purified by column chromatography on silica gel (eluent: dichloromethane/petroleum ether (3:1, v/v) to obtain 4 ( $322 \mathrm{mg}, 35.7 \%$ yield) as a red solid. ${ }^{1} \mathrm{H}$ NMR (400 MHz, $\mathrm{CDCl}_{3}$ ), $\delta$ (ppm): 7.88 (d, $J=$ $8.4 \mathrm{~Hz}, 4 \mathrm{H}), 7.71(\mathrm{~d}, J=8.5 \mathrm{~Hz}, 4 \mathrm{H}), 7.47(\mathrm{~d}, J=8.8 \mathrm{~Hz}, 4 \mathrm{H})$, $7.10(\mathrm{~m}, 8 \mathrm{H}), 6.99$ (d, $J=8.7 \mathrm{~Hz}, 4 \mathrm{H}), 6.85(\mathrm{~m}, 8 \mathrm{H}), 3.95(\mathrm{t}$, $J=6.3 \mathrm{~Hz}, 8 \mathrm{H}), 3.83(\mathrm{~m}, 4 \mathrm{H}), 3.44(\mathrm{t}, J=6.8 \mathrm{~Hz}, 8 \mathrm{H}), 3.34(\mathrm{t}$, $J=6.8 \mathrm{~Hz}, 4 \mathrm{H}), 1.91(\mathrm{~m}, 8 \mathrm{H}), 1.80(\mathrm{~m}, 12 \mathrm{H}), 1.66(\mathrm{dd}$, $J=14.4,7.2 \mathrm{~Hz}, 5 \mathrm{H}), 1.52$ (m, 15H), 1.39 (m, 8H). ${ }^{13} \mathrm{C} \mathrm{NMR}$ $\left(100 \mathrm{MHz}, \mathrm{CDCl}_{3}\right), \delta$ (ppm): 162.89, 155.67, 149.00, 147.99, $140.38,132.31,131.03,130.07,129.20,128.91,127.57$, $126.98,126.56,125.96,120.07,115.34,109.69,67.98$, $41.88,33.88,33.75,32.71,32.54,29.18,27.96,27.64,25.93$, 25.36. LRMS (ESI, $m / z$ ): $[\mathrm{M}+\mathrm{H}]^{+}$calcd. for $\mathrm{C}_{90} \mathrm{H}_{104}{ }^{81} \mathrm{Br}_{3}{ }^{79}$ $\mathrm{Br}_{3} \mathrm{~N}_{4} \mathrm{O}_{6}{ }^{+}$1817.3073, found 1817.2965.

2.1.5 Synthesis of 3,6-bis(4'-(bis(4-((6-azidohexyl) oxy) phenyl)amino)-[1,1'-biphenyl]-4-yl)-2,5-dihexyl-2,5-dihydropyrrolo[3,4-c]pyrrole-1,4-dione (8)

A mixture of $6(238 \mathrm{mg}, 0.14 \mathrm{mmol})$ and sodium azide (111 mg, $1.7 \mathrm{mmol}$ ) was dissolved in $10 \mathrm{~mL}$ dry DMF. The mixture was stirred at $80^{\circ} \mathrm{C}$ under argon atmosphere for $20 \mathrm{~h}$. After cooling to room temperature, the reaction mixture was poured into water and filtered. The resulting filter cake was washed with water and dried in vacuum. The crude product was purified by column chromatography on silica gel (eluent: dichloromethane/petroleum ether $(3: 1, v / v)$ to obtain 8 (177 $\mathrm{mg}, 81.8 \%$ yield) as a red solid. ${ }^{1} \mathrm{H}$ NMR (400 MHz, $\mathrm{CDCl}_{3}$ ), $\delta$ (ppm): 7.89 (d, $\left.J=8.0 \mathrm{~Hz}, 4 \mathrm{H}\right), 7.70$ (d, $J=8.1 \mathrm{~Hz}, 4 \mathrm{H}), 7.47(\mathrm{~d}, J=8.6 \mathrm{~Hz}, 4 \mathrm{H}), 7.10(\mathrm{~d}, J=8.7 \mathrm{~Hz}$, $8 \mathrm{H}), 6.99$ (d, $J=8.3 \mathrm{~Hz}, 4 \mathrm{H}), 6.84(\mathrm{~d}, J=8.8 \mathrm{~Hz}, 4 \mathrm{H}), 3.95$ (t, $J=6.2 \mathrm{~Hz}, 8 \mathrm{H}), 3.88-3.72(\mathrm{~m}, 4 \mathrm{H}), 3.29(\mathrm{t}, J=6.8 \mathrm{~Hz}, 8 \mathrm{H})$, 1.80 (p, $J=6.2 \mathrm{~Hz}, 8 \mathrm{H}), 1.65$ (p, $J=6.9 \mathrm{~Hz}, 12 \mathrm{H}), 1.55-1.41$ (m, 16H), $1.36-1.25(\mathrm{~m}, 12 \mathrm{H}), 0.82(\mathrm{~d}, J=6.8 \mathrm{~Hz}, 3 \mathrm{H}) .{ }^{13} \mathrm{C} \mathrm{NMR}$ $\left(100 \mathrm{MHz}, \mathrm{CDCl}_{3}\right), \delta$ (ppm): 162.91, 155.61, 148.00, 143.39, $140.36,131.13,129.20,127.53,126.93,126.49,126.05$, $120.07,115.29,109.66,67.94,42.15,33.86,32.68,31.24$, $29.46,29.15,27.93,26.44,25.33,22.49,13.99$. Human resource management system (HRMS) (ESI, $m / z):[\mathrm{M}+\mathrm{H}]^{+}$ calcd. for $\mathrm{C}_{90} \mathrm{H}_{107} \mathrm{~N}_{16} \mathrm{O}_{6}^{+} 1507.8560$, found 1507.8525 .

\subsubsection{Synthesis of 2,5-bis(6-azidohexyl)-3,6-bis(4'-(bis (4-} ((6-azidohexyl)oxy)phenyl)amino)-[1,1'-biphenyl]-4-yl)-2,5dihydropyrrolo [3,4-c]pyrrole-1,4-dione (9)

The synthesis was performed following the same procedure of 8 starting with 7 (280 $\mathrm{mg}, 0.15 \mathrm{mmol})$ and sodium azide (120 mg, $1.8 \mathrm{mmol}$ ). The crude product was purified by column chromatography on silica gel (eluent: dichloromethane/petroleum ether $(3: 1, v / v)$ to obtain 9 (227 mg, 92.6\% yield) as a red solid. ${ }^{1} \mathrm{H}$ NMR (400 MHz, $\left.\mathrm{CDCl}_{3}\right), \delta(\mathrm{ppm}): 7.88(\mathrm{~d}, J=8.5 \mathrm{~Hz}, 4 \mathrm{H}), 7.71(\mathrm{~d}, J=8.5 \mathrm{~Hz}$, $4 \mathrm{H}), 7.47$ (d, $J=8.8 \mathrm{~Hz}, 4 \mathrm{H}), 7.10$ (dd, $J=7.2,2.4 \mathrm{~Hz}, 8 \mathrm{H})$, 6.99 (d, $J=8.7 \mathrm{~Hz}, 4 \mathrm{H}), 6.85$ (dd, $J=6.8,1.6 \mathrm{~Hz}, 8 \mathrm{H}), 3.95$ (t, $J=6.3 \mathrm{~Hz}, 8 \mathrm{H}), 3.82$ (t, $J=6.3 \mathrm{~Hz}, 4 \mathrm{H}), 3.29$ (t, $J=6.9 \mathrm{~Hz}$, 
$8 \mathrm{H}), 3.20(\mathrm{t}, J=6.9 \mathrm{~Hz}, 4 \mathrm{H}), 2.00-2.03(\mathrm{~m}, 6 \mathrm{H}), 1.77-1.83$ $(\mathrm{m}, 8 \mathrm{H}), 1.61-1.68(\mathrm{~m}, 16 \mathrm{H}), 1.46-1.54(\mathrm{~m}, 18 \mathrm{H}) .{ }^{13} \mathrm{C} \mathrm{NMR}$ (100 MHz, $\left.\mathrm{CDCl}_{3}\right), \delta(\mathrm{ppm}): 162.89,155.67,149.01,147.99$, $143.52,140.38,132.29,131.02,130.07,129.20,127.56$, $126.98,126.55,125.97,120.07,115.34,109.69$, 67.97, 51.41, 51.31, 29.34, 29.23, 28.83, 28.70, 26.54, 26.32, 26.23, 25.75. HRMS (ESI, $m / z$ ): $[\mathrm{M}+\mathrm{H}]^{+}$calcd. for $\mathrm{C}_{90} \mathrm{H}_{105} \mathrm{~N}_{22} \mathrm{O}_{6}{ }^{+}$ 1589.8587 , found 1589.8573 .

General procedure for the click reaction. To a vigorously stirred solution of $\mathbf{8}(177 \mathrm{mg}, 0.06 \mathrm{mmol})$ and sugar alkyne (177 mg, $0.48 \mathrm{mmol}$ ) in $\mathrm{CH}_{2} \mathrm{Cl}_{2} / \mathrm{H}_{2} \mathrm{O} /$ tert-butanol $(21 \mathrm{~mL}$, $10: 10: 1, \quad v / v / v)$ was added $\mathrm{CuSO}_{4} \cdot 5 \mathrm{H}_{2} \mathrm{O} \quad(120 \mathrm{mg}$, $0.48 \mathrm{mmol}$ ) and sodium ascorbate (180 $\mathrm{mg}, 0.96 \mathrm{mmol})$. The reaction mixture was stirred at $50{ }^{\circ} \mathrm{C}$ for $12 \mathrm{~h}$, and then an aqueous solution of EDTA $(5 \mathrm{~mL})$ was added dropwise after the reaction was cooled to room temperature. Then the mixture was extracted by dichloromethane $(3 \times 15 \mathrm{~mL})$. The combined organic layer was washed with saturated brine and dried over $\mathrm{Na}_{2} \mathrm{SO}_{4}$. After removal of the solvent, the crude product was purified by column chromatography on silica gel.

\subsubsection{Synthesis of compound $\mathbf{1 0}$}

From 8 (186 mg, $0.12 \mathrm{mmol})$ and galctose alkyne (177 mg, $0.48 \mathrm{mmol}$ ), column chromatography (eluent: dichloromethane/methanol (20:1, v/v) gave 10 (204 mg, 64.9\% yield) as a red solid. ${ }^{1} \mathrm{H} \mathrm{NMR}\left(400 \mathrm{MHz}, \mathrm{CDCl}_{3}\right), \delta(\mathrm{ppm})$ : 7.89 (dd, $J=8.0,4.0 \mathrm{~Hz}, 4 \mathrm{H}$ ), 7.70 (dd, $J=8.0,0.8 \mathrm{~Hz}, 4 \mathrm{H})$, 7.52 (s, 4H), 7.47 (dd, J=7.2, $1.8 \mathrm{~Hz}, 4 \mathrm{H}), 7.09$ (d, $J=8.7 \mathrm{~Hz}$, $8 \mathrm{H}), 7.02-6.94(\mathrm{~m}, 4 \mathrm{H}), 6.89-6.73(\mathrm{~m}, 8 \mathrm{H}), 5.40(\mathrm{~d}, J=$ $3.2 \mathrm{~Hz}, 4 \mathrm{H}), 5.23(\mathrm{t}, J=8.7 \mathrm{~Hz}, 4 \mathrm{H}), 5.06-4.97(\mathrm{~m}, 4 \mathrm{H})$, $4.88-4.76(\mathrm{~m}, 4 \mathrm{H}), 4.67(\mathrm{t}, J=7.7 \mathrm{~Hz}, 4 \mathrm{H}), 4.44-4.31(\mathrm{~m}$, $8 \mathrm{H}), 4.24-4.05(\mathrm{~m}, 12 \mathrm{H}), 4.00-3.89(\mathrm{~m}, 12 \mathrm{H}), 3.86-3.75(\mathrm{~m}$, $4 \mathrm{H}), 2.25-2.18(\mathrm{~m}, 4 \mathrm{H}), 2.15(\mathrm{~s}, 12 \mathrm{H}), 2.05$ (d, $J=5.5 \mathrm{~Hz}$, 20H), 2.00 (s, 12H), 1.98 (s, 12H), 1.96-1.90 (m, 4H), 1.83$1.74(\mathrm{~m}, 16 \mathrm{H}), 1.48-1.38(\mathrm{~m}, 16 \mathrm{H}), 0.87(\mathrm{t}, J=4.0 \mathrm{~Hz}, 6 \mathrm{H})$. ${ }^{13} \mathrm{C}$ NMR $\left(100 \mathrm{MHz}, \mathrm{CDCl}_{3}\right), \delta$ (ppm): 170.54, 170.45, $170.34,170.25,170.12,170.04,169.55,162.93,155.59$, $148.91,148.01,144.23,140.45,131.24,129.22,127.61$, $127.57,126.92,126.52,122.48,120.14,115.31,109.71$, $100.49,95.60,70.84,68.81,67.99,67.86,67.52,67.06$, $63.10,61.59,61.43,61.29,50.31,31.25,30.29,29.48,29.14$, 26.44, 26.31, 25.63, 22.49, 20.80, 20.72, 20.68, 20.59, 13.98 . HRMS (MALDI, $m / z$ ): [M] calcd. for $\mathrm{C}_{158} \mathrm{H}_{194} \mathrm{~N}_{16} \mathrm{O}_{46}$ : 3501.3333, found: 3051.3374 .

\subsubsection{Synthesis of compound 11}

From 9 (113 mg, $0.03 \mathrm{mmol})$ and galactose alkyne $(170 \mathrm{mg}$, $0.42 \mathrm{mmol}$ ), column chromatography (eluent: dichloromethane/methanol (20:1, v/v) gave 11 (143 mg, 51.6\% yield) as a red solid. ${ }^{1} \mathrm{H} \mathrm{NMR}\left(400 \mathrm{MHz}, \mathrm{CDCl}_{3}\right), \delta$ (ppm): $7.86(\mathrm{~d}, J=8.1 \mathrm{~Hz}, 4 \mathrm{H}), 7.71(\mathrm{~d}, J=8.2 \mathrm{~Hz}, 4 \mathrm{H}), 7.55(\mathrm{~s}, 4 \mathrm{H})$, 7.52 (s, 2H), 7.48 (d, J=2.5 Hz, 4H), 7.09 (d, J=8.8 Hz, 8H), $6.98(\mathrm{dd}, J=8.8,1.5 \mathrm{~Hz}, 4 \mathrm{H}), 6.84$ (d, $J=8.9 \mathrm{~Hz}, 8 \mathrm{H}), 5.42-$ $5.32(\mathrm{~m}, 24 \mathrm{H}), 5.26-5.19(\mathrm{~m}, 10 \mathrm{H}), 5.18-5.09(\mathrm{~m}, 6 \mathrm{H}), 4.83$ (t, $J=12.9 \mathrm{~Hz}, 6 \mathrm{H}), 4.71-4.63(\mathrm{~m}, 6 \mathrm{H}), 4.39(\mathrm{t}, J=7.4 \mathrm{~Hz}$, $10 \mathrm{H}), 3.94(\mathrm{t}, J=5.4 \mathrm{~Hz}, 12 \mathrm{H}), 3.81$ (t, $J=4.0 \mathrm{~Hz}, 4 \mathrm{H}), 2.07-$ $2.03(\mathrm{~m}, 40 \mathrm{H}), 2.01(\mathrm{dd}, J=5.8,4.0 \mathrm{~Hz}, 25 \mathrm{H}), 1.97$ (dd, $\mathrm{J}=7.0,2.2 \mathrm{~Hz}, 35 \mathrm{H}), 1.84-1.74(\mathrm{~m}, 10 \mathrm{H}), 1.47-1.40(\mathrm{~m}$, 10H). ${ }^{13} \mathrm{C}$ NMR $\left(100 \mathrm{MHz}, \mathrm{CDCl}_{3}\right), \delta(\mathrm{ppm}): 170.55$, $170.35,170.25,170.06,170.01,155.65,140.38,129.18$, $129.12,127.54,126.98,126.82,126.56,125.90,122.54$, $115.31,95.60,70.84,67.99,67.93,67.87,67.51,67.06$, $67.01,66.46,61.59,61.43,61.27,54.45,53.45,50.34,50.24$, $30.30,30.10,29.15,26.34,26.19,26.02,25.63,20.80,20.77$, 20.67, 20.60. HRMS (MALDI, $m / z$ ): [M] calcd. for $\mathrm{C}_{192} \mathrm{H}_{236} \mathrm{~N}_{22} \mathrm{O}_{66}: 3905.5787$, found: 3905.5884 .

General procedure for the deacylation. To a solution of the acetyl intermediates in a mixed solvent of methanol $(1.6 \mathrm{~mL})$ and $\mathrm{H}_{2} \mathrm{O}(0.18 \mathrm{~mL})$ was added triethylamine $(0.18 \mathrm{~mL}$, $0.65 \mathrm{mmol}$ ), and the reaction mixture was stirred at $\mathrm{rt}$. for $24 \mathrm{~h}$. After removal of the solvent, the crude product was purified by column chromatography on silica gel.

\subsubsection{Synthesis of compound DPPF-G}

From 10 (204 mg, $0.05 \mathrm{mmol}$ ), column chromatography (eluent: dichloromethane/methanol $(4: 1, v / v)$ gave DPPF-G (44 mg, 26.7\% yield) as a dark-red solid. ${ }^{1} \mathrm{H}$ NMR (400 MHz, DMSO- $\left.d_{6}\right) \delta 8.12(\mathrm{~s}, 4 \mathrm{H}), 7.90(\mathrm{~d}, J=8.3 \mathrm{~Hz}, 4 \mathrm{H})$, $7.82(\mathrm{~d}, J=8.5 \mathrm{~Hz}, 4 \mathrm{H}), 7.64(\mathrm{~d}, J=8.6 \mathrm{~Hz}, 4 \mathrm{H}), 7.08$ (d, $J=$ $8.9 \mathrm{~Hz}, 8 \mathrm{H}), 6.93$ (d, J=9.0 Hz, 8H), 6.83 (d, $J=9.1 \mathrm{~Hz}, 4 \mathrm{H})$, 4.86-4.71 (m, 4H), 4.61 (d, $J=12.1 \mathrm{~Hz}, 4 \mathrm{H}), 4.35$ (t, $J=$ $7.0 \mathrm{~Hz}, 10 \mathrm{H}), 4.20(\mathrm{~d}, J=7.2 \mathrm{~Hz}, 4 \mathrm{H}), 3.94$ (t, $J=6.1 \mathrm{~Hz}$, $10 \mathrm{H}), 3.77$ (dd, $J=9.5,3.9 \mathrm{~Hz}, 4 \mathrm{H}), 3.70$ (d, $J=2.8 \mathrm{~Hz}, 3 \mathrm{H})$, $3.66-3.59$ (m, 9H), 3.57-3.49 (m, 8H), 2.00 (q, $J=7.0 \mathrm{~Hz}$, $4 \mathrm{H}), 1.84$ (p, $J=7.0,6.6 \mathrm{~Hz}, 8 \mathrm{H}), 1.78-1.63(\mathrm{~m}, 8 \mathrm{H}), 1.45$ (p, $J=8.5,7.5 \mathrm{~Hz}, 16 \mathrm{H}), 1.30(\mathrm{dd}, J=16.1,8.0 \mathrm{~Hz}, 12 \mathrm{H}), 0.75$ (t, $J=6.4 \mathrm{~Hz}, 6 \mathrm{H}) .{ }^{13} \mathrm{C}$ NMR $\left(100 \mathrm{MHz}, \mathrm{DMSO}-d_{6}\right), \delta(\mathrm{ppm})$ : $161.63,155.73,155.54,143.79,139.44,130.14,129.20$, $127.47,127.17,125.79,124.01,118.67,115.52,108.73$, $108.63,102.70,99.73,75.30,73.89,73.40,71.40,70.46$, $68.13,67.50,61.50,61.43,60.47,49.21,48.44,30.47,29.66$, 28.53, 28.46, 25.62, 24.97, 21.80, 13.75. HRMS (MALDI, $m / z)$ : [M] calcd. for $\mathrm{C}_{126} \mathrm{H}_{162} \mathrm{~N}_{16} \mathrm{O}_{30}: 2379.1643$, found: 2379.1619 .

\subsubsection{Synthesis of compound DPPS-G}

From 11 (120 mg, $0.03 \mathrm{mmol})$, column chromatography (eluent: dichloromethane/methanol $(1: 1, v / v)$ gave DPPS-G (60 mg, 69.7\% yield) as a dark-red solid. ${ }^{1} \mathrm{H}$ NMR (400 MHz, DMSO- $d_{6}$ ), $\delta$ (ppm): 8.13 (s, 4H), 8.05 (s, 2H), $7.91(\mathrm{~d}, J=7.8 \mathrm{~Hz}, 4 \mathrm{H}), 7.83(\mathrm{~d}, J=7.8 \mathrm{~Hz}, 4 \mathrm{H}), 7.65$ (d, $J=$ $8.9 \mathrm{~Hz}, 4 \mathrm{H}), 7.09$ (d, $J=8.7 \mathrm{~Hz}, 8 \mathrm{H}), 6.94$ (d, $J=8.9 \mathrm{~Hz}, 8 \mathrm{H})$, $6.83(\mathrm{~d}, J=8.2 \mathrm{~Hz}, 4 \mathrm{H}), 4.82-4.71(\mathrm{~m}, 8 \mathrm{H}), 4.67-4.46(\mathrm{~m}$, $25 \mathrm{H}), 4.42-4.32(\mathrm{~m}, 15 \mathrm{H}), 4.22(\mathrm{dt}, J=21.2,5.8 \mathrm{~Hz}, 6 \mathrm{H})$, $3.94(\mathrm{t}, J=6.2 \mathrm{~Hz}, 8 \mathrm{H}), 3.70$ (q, $J=5.2,4.3 \mathrm{~Hz}, 5 \mathrm{H}), 3.67-$ 
$3.56(\mathrm{~m}, 11 \mathrm{H}), 1.91-1.79(\mathrm{~m}, 9 \mathrm{H}), 1.75-1.62(\mathrm{~m}, 13 \mathrm{H}), 1.45$ (dt, $J=14.3,8.0 \mathrm{~Hz}, 13 \mathrm{H}), 1.37-1.26(\mathrm{~m}, 13 \mathrm{H}) .{ }^{13} \mathrm{C}$ NMR $\left(100 \mathrm{MHz}, \mathrm{DMSO}-d_{6}\right), \delta$ (ppm): 155.54, 143.84, 139.44, $129.62,129.50,129.23,127.50,127.20,126.19,125.83$, $125.50,124.01,123.75,116.92,115.52,108.61,102.69$, $98.32,75.30,73.39,71.39,70.45,70.43,69.51,68.85,68.26$, $68.15,67.50,60.63,60.50,60.01,49.23,49.10,29.64,29.45$, 28.54, 25.63, 25.45, 25.28, 24.97. HRMS (MALDI, $m / z$ ): [M] calcd. for $\mathrm{C}_{144} \mathrm{H}_{188} \mathrm{~N}_{22} \mathrm{O}_{42}: 2897.3251$, found: 2897.3906 .

\subsection{UV-Vis and fluorescent (FL) spectra}

The absorption spectra were measured with a Varian Cary $500 \mathrm{UV}-\mathrm{Vis}$ spectrophotometer (USA). Fluorescent spectra were measured with a Horiba Fluoromax-4 Fluorescence spectrometer (Japan). Stock solutions of glycol-DPPs were prepared in DMSO $(1 \mathrm{mM})$. Aliquots of the stock solution were transferred to $1.0 \mathrm{~mL}$ volumetric flasks. After addition of appropriate amounts of DMSO, water was added dropwise under vigorous stirring to furnish $1.0 \times 10^{-5} \mathrm{M}$ solutions with different water fractions (0-99 vol\%). The UV and FL measurements of the resulting solutions were then performed immediately.

\subsection{Fluorescence titration measurements}

Stock solutions of glyco-DPPs were prepared in DMSO (0.1 mM). Selective lectin PNA (for DPPG, DPPF-G and DPPS-G) was dissolved in $0.1 \mathrm{mM}, \mathrm{pH} 7.2$ Tris-HCl buffer ( $50 \mathrm{mM}$ Tris). Fluorescence titrations were carried out by sequential addition of $0-200 \mu \mathrm{L}$ aliquots of lectins solution to a $10 \mu \mathrm{L}$ stock solution of glycol-DPPs followed by the addition of Tris- $\mathrm{HCl}$ buffer to acquire a solution of $1.0 \mathrm{~mL}$. The final concentration of gylco-DPPs was $1.0 \times 10^{-6} \mathrm{M}$. The FL measurements of the resulting solutions were then performed immediately.

\subsection{Calculation of LOD}

By plotting the ratio of fluorescence intensity as a function of lectin concentration, the limit of detection (LOD) was calculated by the equation $3 \delta$ /slope ( $\delta$ is a standard deviation of the measured value of the emission maxima of blank solution for seven times).

\subsection{Selectivity measurements}

Equal concentrations of other proteins $(10 \mu \mathrm{M})$ including LcA, ConA, PNA, trypsin (Try), cytochrome C (CyC), bovine serum albumin (BSA), and RNase A (RNA) and physiological ions $(100 \mu \mathrm{M})$ including $\mathrm{K}^{+}, \mathrm{Na}^{+}, \mathrm{Ca}^{2+}, \mathrm{Mg}^{2+}$, $\mathrm{Mn}^{2+}, \mathrm{Cl}^{-}, \mathrm{Br}^{-}, \mathrm{I}^{-}, \mathrm{CO}_{3}{ }^{2-}, \mathrm{AcO}^{-}$were added to glyco-DPP solutions $(1 \mu \mathrm{M})$. The FL measurements of the resulting solutions were performed immediately.

\subsection{Dynamic light scattering analysis and scanning electron microscope}

Dynamic light scattering analysis (DLS) was measured by a Zetasizer Nano ZS90 (UK). Gylco-DPPs were prepared as $1.0 \times 10^{-6} \mathrm{M}$, and then different aliquots of lectins solutions were added. The DLS measurements of the resulting solutions were then performed immediately. The SEM images were recorded with a JEOL JSM-6360 scanning electron microscope (Japan). The samples used were prepared by dispersion on quartz plate, and then dried at room temperature prior to measurement.

\subsection{Cell culture}

HepG2 and HeLa cells were cultured in T-25 flasks with Dulbecco's Modified Eagle's Medium (DMEM, Gibco), $10 \%$ heat-inactivated fetal bovine serum (FBS, Gibco), $100 \mathrm{U} \mathrm{mL}^{-1}$ penicillin (Gibco), and $100 \mu \mathrm{g} \mathrm{mL}^{-1}$ streptomycin (Gibco). Cells were incubated at $37{ }^{\circ} \mathrm{C}$ in an ambient air and $5 \% \mathrm{CO}_{2}$ atmosphere until $80 \%$ confluence was reached prior to use.

\subsection{Cytotoxicity studies}

Methylthiazolyldiphenyltetrazolium bromide (MTT) assays were used to assess the viability of HepG2 cells after incubation with the probe. The cells in 96-well plates (Costar, IL, USA) were first incubated with the probe for designated time in the dark. The cells were further incubated in fresh medium for $24 \mathrm{~h}$ and washed with phosphate buffer saline (PBS). Then MTT in PBS solution $\left(100 \mu \mathrm{L}, 0.5 \mathrm{mg} \mathrm{mL}^{-1}\right)$ was added into each well. After incubation for $3 \mathrm{~h}$, the supernatant was discarded and the precipitate was dissolved in DMSO $(100 \mu \mathrm{L})$ with gentle shaking. The absorbance of MTT at $570 \mathrm{~nm}$ was monitored by the microplate reader (Genios Tecan).

\section{Results and discussion}

\subsection{Synthesis of DPPG, DPPF-G and DPPS-G}

The synthesis of DPPG follows the previous report [34]. The target compounds were synthesized through coupling between alkyl substituted-triphenylamine and alkyl-DPP cores, which was followed by the reaction with alkynyl galactoside via the $\mathrm{Cu}(\mathrm{I})$-catalyzed azide-alkyne 1.3-dipolar cycloaddition (Scheme 1). Firstly, 1,6-dibromohexane was introduced to 4,4'-((4-bromophenyl)azanediyl)diphenol (1) by an electrophilic substitution reaction to form compound $\mathbf{2}$, which was treated with triisopropyl borate to yield $\mathbf{3}$. In the second step, two different alkyl-DPPs were synthesized according to 


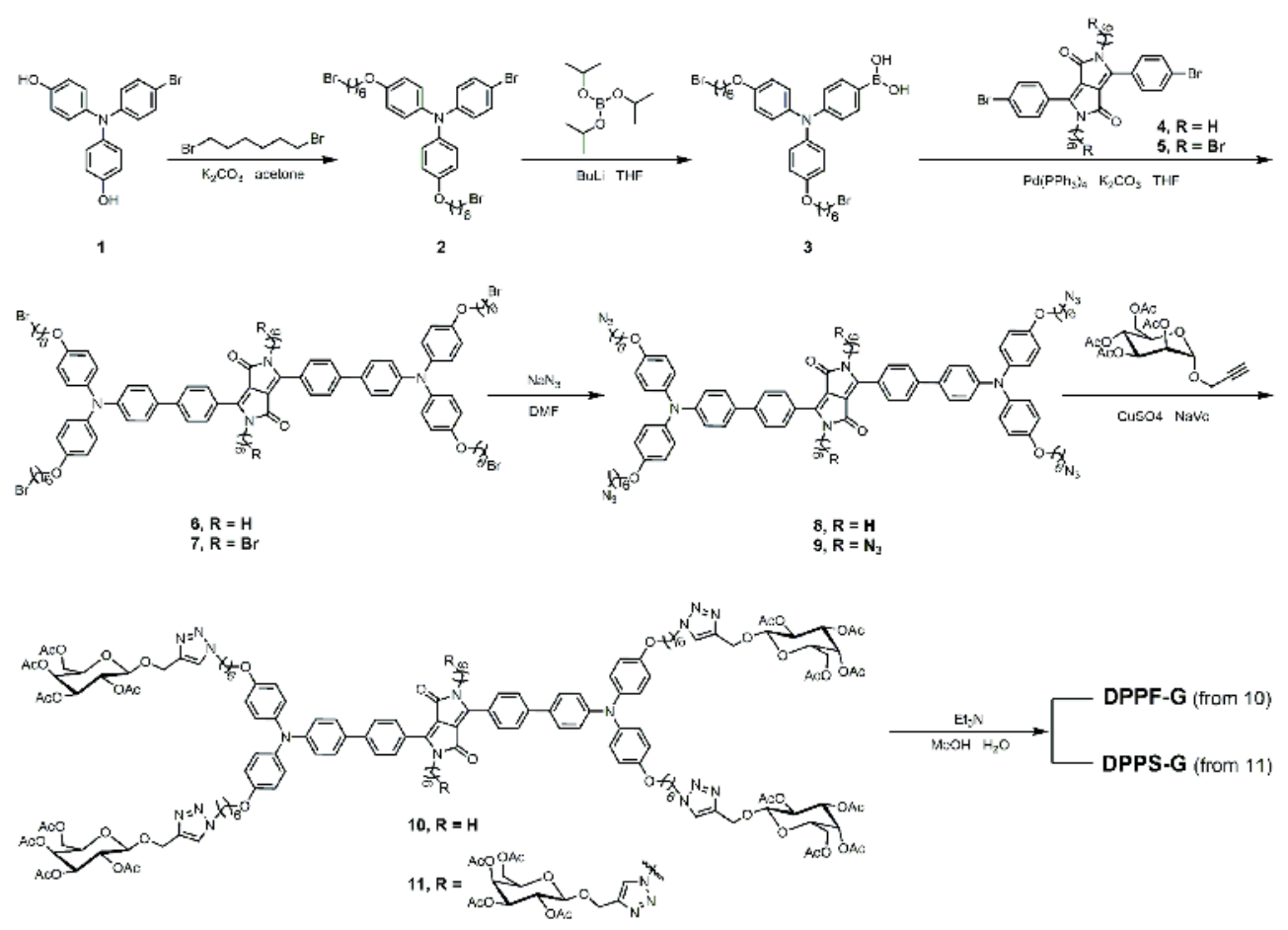

Scheme 1 Synthesis of DPPF-G and DPPS-G.

literature protocols. Palladium-mediated Suzuki cross-coupling between 3 and alkyl-DPPs gave bromides 6 and 7, which were reacted with an azide in DMF to produce the azido DPP intermediates 8 and 9 (Scheme 1). Copper-catalyzed azide-alkyne 1,3-dipolarcycloaddition reaction between 8 or 9 and galactose alkyne led to the formation of glycosyl 10 and $\mathbf{1 1}$ in good yields. Finally, deacetylation of $\mathbf{1 0}$ and $\mathbf{1 1}$ yielded the desired divalent galactosyl DPPF-G and DPPS-G (Scheme 1). All the new compounds were well characterized by ${ }^{1} \mathrm{H}$ NMR, ${ }^{13} \mathrm{C}$ NMR, and HRMS (see Supporting Information online).

\subsection{Optical property measurements}

The UV-Visible absorption and fluorescent spectra of DPPSG and DPPF-G were measured in DMSO/ $\mathrm{H}_{2} \mathrm{O}$ mixtures. The absorption maxima $\left(\lambda_{\text {abs }}\right)$ of DPPS-G and DPPF-G in pure DMSO solution are located at 519 and $525 \mathrm{~nm}$, respectively (Figure 1(a,d)). With the increased water fraction $\left(f_{\mathrm{w}}\right.$, the volume percentage of water in $\mathrm{DMSO} /$ water mixtures), their UV absorption spectra become broader, which indicate the slight aggregates formation of DPPS-G and DPPF-G in DMSO/water. However, the change in the absorption spectrum of DPPS-G is less significant than that of DPPF-G, due to the better water solubility of the former. DPPS-G is nearly non-emissive in pure DMSO and low water fraction mixtures $\left(f_{\mathrm{w}} \leq 30 \%\right)$, but exhibits distinct fluorescence in NIR region (located around $721 \mathrm{~nm}$ ) when $f_{\mathrm{w}}$ is $\geq 40 \%$ and continues to increase until $f_{\mathrm{w}}$ is $99 \%$ (Figure $2(\mathrm{a}-\mathrm{c})$ ). The emission properties of DPPF-G are slightly different from those of DPPS-G (Figure 2(d-f)). The fluorescence enhancement of DPPF-G is observed when $f_{\mathrm{w}}$ is $30 \%$ and saturates at $f_{\mathrm{w}}=60 \%$ (Figure 2(f)). Meanwhile, its maximum emission wavelength is located at $679 \mathrm{~nm}$, which is relatively shorter than DPPS-G. Therefore, both DPPS-G and DPPF-G show typical AIE characteristics. Additionally, the UV and PL spectra of DPPG were also plotted to compare with those for DPPS-G and DPPF-G. As shown in Figure 2(g-i), in DMSO, DPPG is nearly non-emissive and its $\lambda_{\text {abs }}$ is centered at $521 \mathrm{~nm}$. With low water fractions $\left(f_{\mathrm{w}}<30 \%\right)$, the FL and absorption maxima remain unchanged. In contrast, when $f_{\mathrm{w}}$ is higher than $30 \%$, evident FL enhancement in the NIR region is observed, which saturates at $f_{\mathrm{w}}=50 \%$. However, the FL intensity of the DPPG deceases with further increase of $f_{\mathrm{w}}(50 \%-90 \%)$. Upon addition of water, at the low $f_{\mathrm{w}}$, the DPP molecules tend to aggregate which limits the intramolecular rotations to enhance its fluorescence by AIE. However, while in a mixture with higher water ratio, the hydrophobic DPPs quickly aggregate in a random way to form less emissive and smaller particles, which lead to the decrease of FL [41]. However, this phenomenon was not observed for DPPS-G since only very small aggregates could form even in the $99 \%$ Tris- $\mathrm{HCl}$ buffer due to the presence of six galactoses in each molecule, which was also confirmed by DLS experiments (Table S1, Figure S1, Supporting Information online).

\subsection{Detection of lectin}

As the galactose is specifically recognized by peanut ag- 

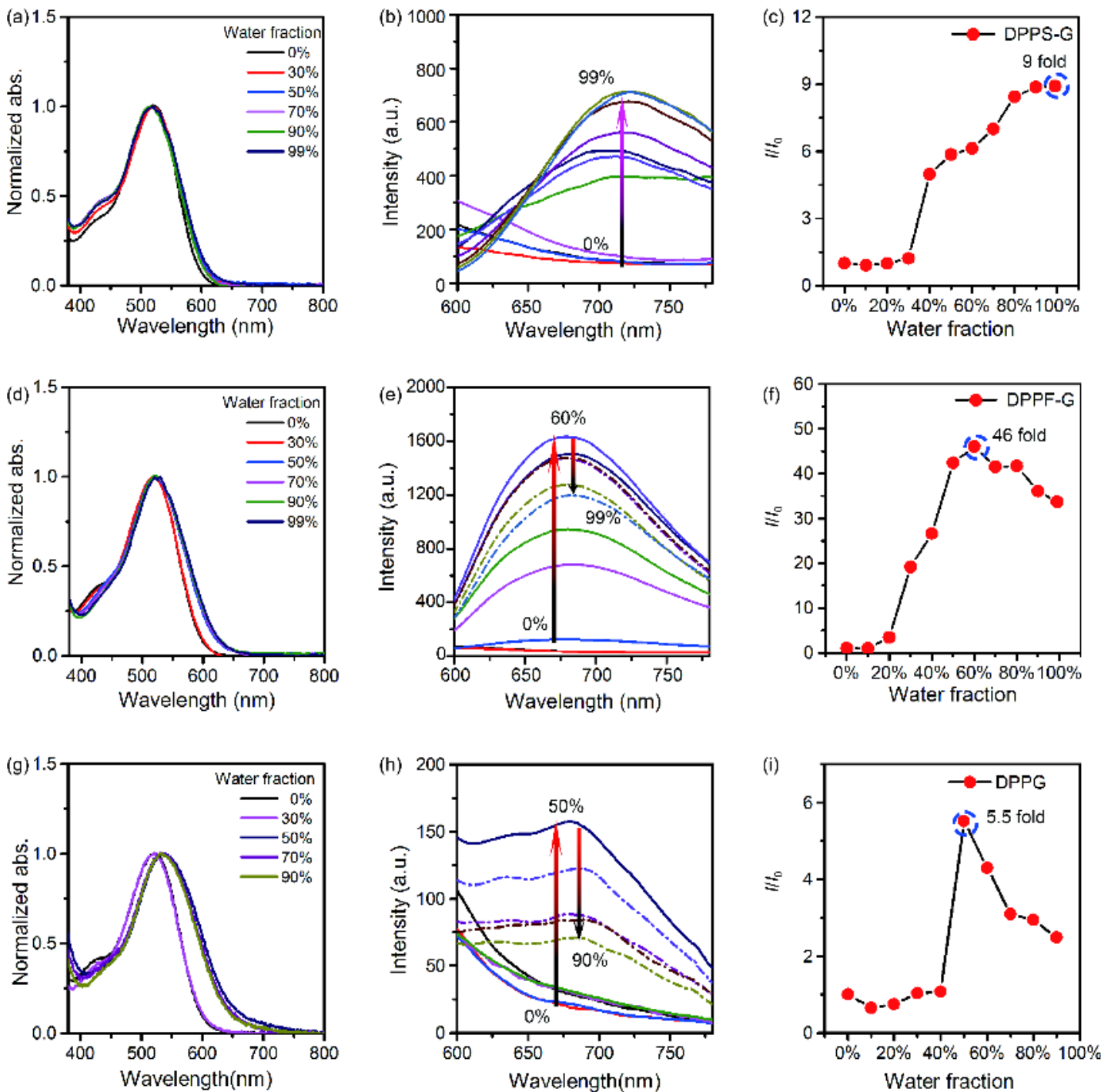

Figure 2 Normalized UV-absorption spectra of (a) DPPS-G, (d) DPPF-G and (g) DPPG. Fluorescence (FL) emission spectra of (b) DPPS-G, (e) DPPF-G and (h) DPPG in DMSO with increasing water fractions (0-99 vol\%). Plotting the ratio of $I / I_{0}\left(I_{0}\right.$ refers to value of the emission maxima in pure DMSO) change of (c) DPPS-G, (f) DPPF-G and (i) DPPG in DMSO as a function of increasing water fractions. Emission maxima: 721,679 and $681 \mathrm{~nm}$, respectively. Figure (g)-(i) reprinted with permission from Ref. [34], Copyright 2015, Elsevier (color online).

glutinin (PNA), the plant lectin was used to perform biosensing. As shown in Figure 3(a), when addition of PNA to DPPS-G solutions, DPPS-G was induced to aggregate due to the interaction of galactoside with the sugar-recognized region of PNA, thus led to a sharp increase of the FL intensity. Although DPPF-G has a relatively strong emission in Tris-HCl buffer (containing $50 \mathrm{mM}$ Tris, 1\% DMSO, $\mathrm{pH}$ 7.2), the fluorescence intensity could still enhance gradually when PNA is added (shown in Figure 3(d)). Similarly, addition of PNA into DPPG also leads to sharp and concentration-dependent increase of the FL in the NIR region. However, the fluorescence enhancement has level off when 8-10 eq. PNA was added, and the emission maximum of DPPS-G is blue-shift by about $52 \mathrm{~nm}$ (Figure 3(a)), while only slight blue-shift is observed for both DPPF-G and
DPPG (Figure 3(d, g)). As DPP with more sugar groups have higher affinities with lectins, the difference in the blueshift is due to much more distinct aggregates of DPP molecules in the presence of lectins as indicated by SEM images (Figure 4(a-f)). The aggregates formation provides better protection of DPP molecules from polar environment to limit the intramolecular charge transfer (ICT) effect arising from the D-A-D (D represents donor and A represents accepter) structure and eventually leads to more obvious blue shift in the FL spectra for DPPS-G. In addition, the plots of FL of glyco-DPPs at their own emission maximum were found to be linear against the concentration of lectins at low concentration range $(0.0-6.0 \mu \mathrm{M})$. The limits of detection (LOD) of DPPS-G, DPPF-G and DPPG for PNA were determined to be 18,12 and $11 \mathrm{nM}$, respectively 

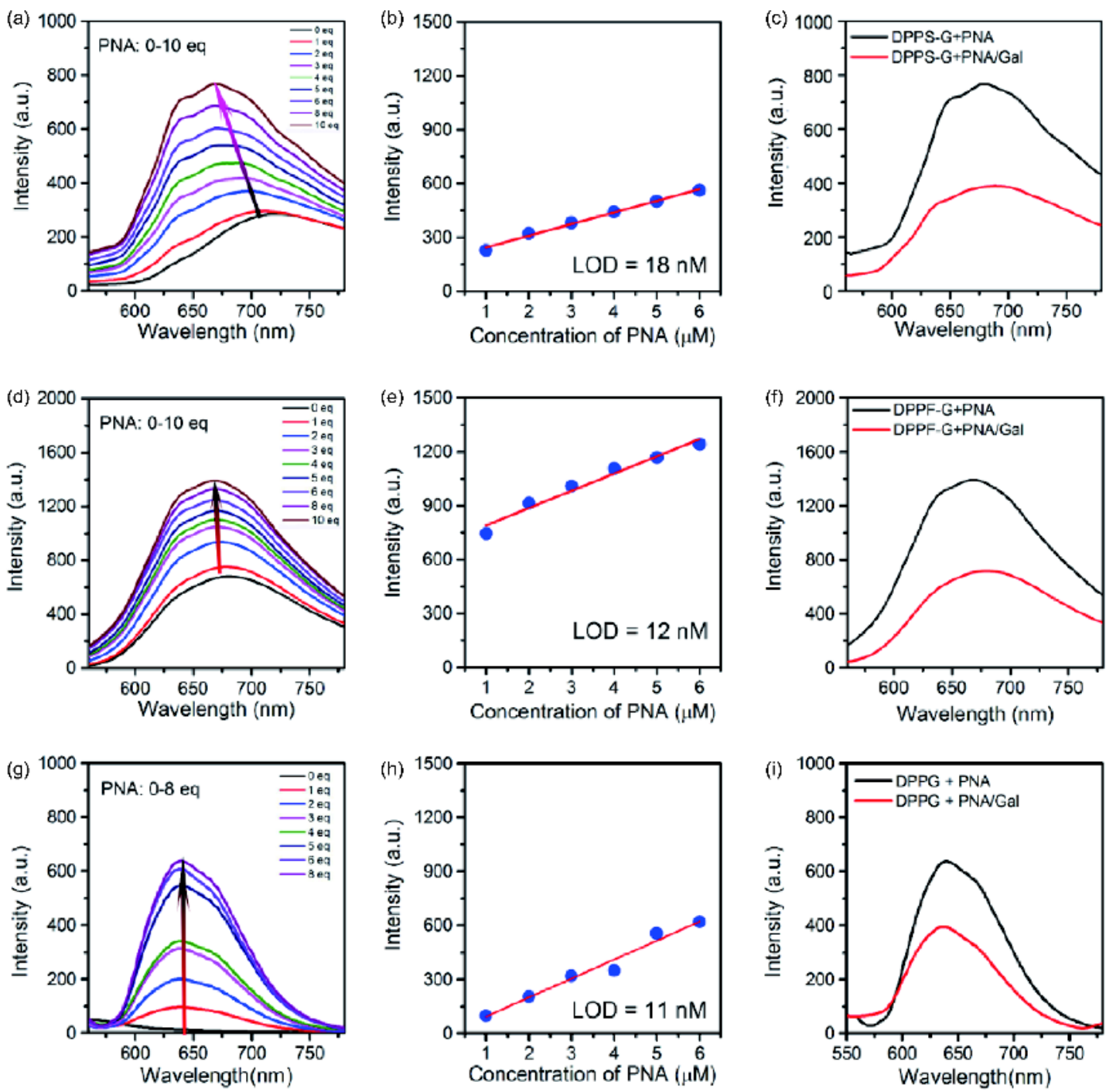

Figure 3 Fluorescence (FL) titration spectra of (a) DPPS-G $(1 \mu \mathrm{M})$, (d) DPPF-G $(1 \mu \mathrm{M})$ and $(\mathrm{g})$ DPPG $(1 \mu \mathrm{M})$ in the presence of increasing peanut agglatinin (PNA). Plotting the FL as a function of lectin concentration for determination of the limit of detection (LOD) of (b) DPPS-G, (e) DPPF-G and (h) DPPG for PNA. FL spectra of (c) DPPS-G $(1 \mu \mathrm{M})$, (f) DPPF-G $(1 \mu \mathrm{M})$ and (i) DPPG $(1 \mu \mathrm{M})$ in the absence and presence of PNA (10 $\mu \mathrm{M})$ or pretreated PNA with $D$-galactose $(100 \mu \mathrm{M})$. FLs were measured in $1 \% \mathrm{DMSO} / 99 \%$ Tris- $\mathrm{HCl}$ buffer. $\lambda_{\mathrm{ex}}=520 \mathrm{~nm}$ for DPPF-G, $\lambda_{\mathrm{ex}}=525 \mathrm{~nm}$ for DPPG and DPPS-G. Figure (g)-(i) reprinted with permission from Ref. [34], Copyright 2015, Elsevier (color online).

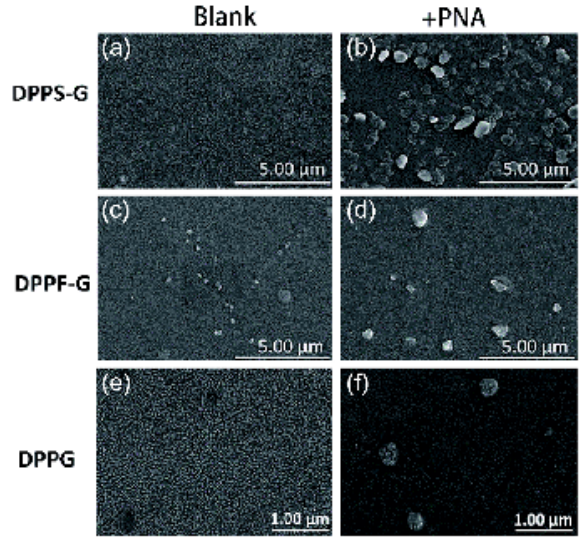

Figure 4 Scanning electronic microscope imaging of (a) DPPS-G, (c) DPPF-G, (e) DPPG, (b) DPPS-G+PNA, (d) DPPF-G+PNA and (f) DPPG + PNA. Figure $(e, f)$ reprinted with permission from Ref. [34], Copyright 2015, Elsevier.
(Figure 3(b, e, h)).

\subsection{Dynamic light scattering and SEM images}

To understand the sensing mechanism of DPP-based probes, the morphology variation of the three probes' aggregates was visualized by SEM images. From the SEM images (Figure 4), the sizes of the aggregates of DPPs are much larger in the presence of lectins. The results further indicate that the enhancement of fluorescence of DPPs is attributed to the formation of aggregates based on selective sugar-lectin interactions (Scheme 2). The DPPS-G and DPPF-G functionalized with more galactose have shown better binding efficiency, leading to larger aggregates in the presence of PNA. Furthermore, DLS analysis was used to investigate the aggregation process of DPPS-G and DPPF-G in the pre- 


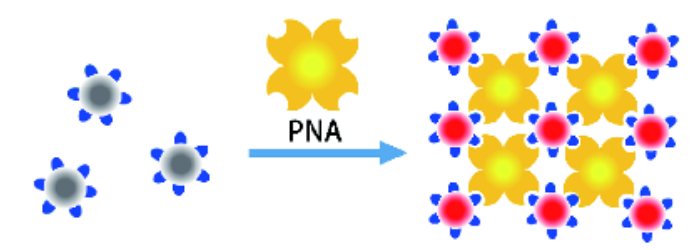

Weak fluorescence

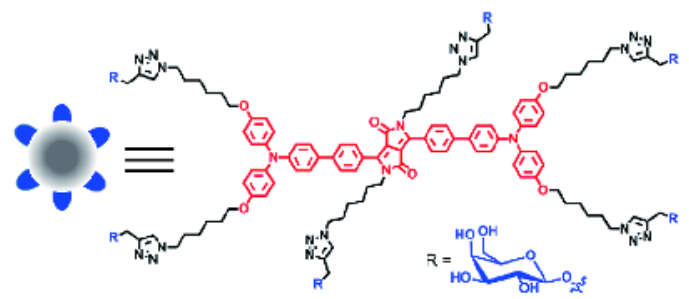

Scheme 2 The illustrate of the AIE mechanism (color online).

sence of PNA. The data were summarized in Table S2. As shown in Figure S3(a), the hydrodynamic diameters of DPPS-G increase gradually from 8.5 to $462.1 \mathrm{~nm}$ after PNA addition. Under the same conditions, the size of DPPF-G also increases from 23.4 to $503 \mathrm{~nm}$ (Figure S3(b)). It is worth noting that DPPS-G with more galactose dissolves better in water, resulting in smaller particles than DPPF-G.

\subsection{Targeting the HepG2 cells and fluorescence ima- ging}

At the molecular level, all three probes can detect PNA with good sensitivity and selectivity by sugar-glycoprotein interaction. Subsequently, their ability in probing specific recognitions between sugar ligands and glycoprotein receptors on cancer cells was evaluated. Cell experiments with DPPG, DPPF-G and DPPS-G were carried out to evaluate the up- take ability of the three probes using HepG2 cells as an example, which express a substantial amount of galactose receptor (ASGP-Rs) on the surface. After incubation with DPPG, DPPF-G or DPPS-G solutions $(10 \mu \mathrm{M}$ in PBS buffer, $\mathrm{pH} 7.4$ ) for $30 \mathrm{~min}$ at $37^{\circ} \mathrm{C}$ in the culture medium, HepG2 cells were subsequently imaged by CLSM with $530 \mathrm{~nm}$ laser excitation and the fluorescent signals were collected from 600 to $800 \mathrm{~nm}$. The HeLa cells were used as a negative control at the same time. As shown in Figure 5(a2, a3), red fluorescence is observed in HepG2 cells incubated with DPPF-G and DPPS-G. The fluorescence of DPPS-G is distributed evenly in cytoplasm region and is stronger than DPPF-G. However, only very weak red fluorescence could be observed from HepG2 cells incubated with DPPG under the same condition (Figure 5(a1)). Additionally, almost no red fluorescence could be observed in HeLa cells (Figure 5(d1-d3)). These results suggest that galactose functionalized DPP dyes have the ability to target HepG2 cells and glycol-DPPs with more galactose groups have more binding sites so that they are more efficient in interacting with the target cells.

As low toxicity is essential for probes applied in biosystems, the cytotoxicity of these three probes was also evaluated by MTT assay. As shown in Figure 6, cell viability was over $90 \%$ after $24 \mathrm{~h}$ incubation of the cells with probes at a concentration of $20 \mu \mathrm{M}$, which reveals that the glyco-DPP dyes have very low toxicity to cells.

\section{Conclusions}

In summary, three glyco-DPPs fabricated with two (DPPG), four (DPPF-G) and six (DPPS-G) galactose groups have been developed. All three molecules could probe lectins with

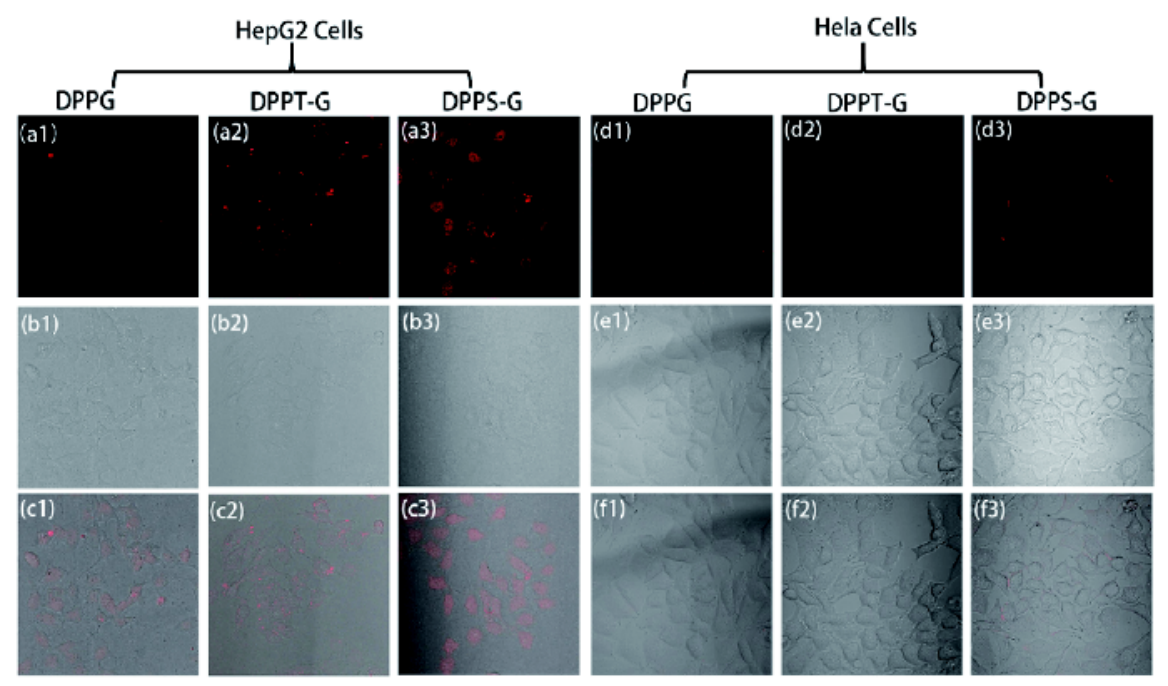

Figure 5 Confocal laser scan imaging of HepG2 cells incubated with DPPG (a1-c1), DPPF-G (a2-c2) and DPPS-G (a3-c3) in PBS, pH 7.4, $37^{\circ} \mathrm{C}$. Confocal laser scan imaging of HeLa cells incubated with DPPG (d1-f1), DPPF-G (d2-f2) and DPPS-G (d3-f3) in PBS, pH 7.4, $37^{\circ} \mathrm{C}$. Dark field: a1-a3 and d1-d3. Bright field: b1-b3 and e1-e3. Merged: c1-c3 and f1-f3. $\lambda_{\mathrm{ex}}=530 \mathrm{~nm}, \lambda_{\mathrm{em}}$ collected: $600-800 \mathrm{~nm}$ (color online). 

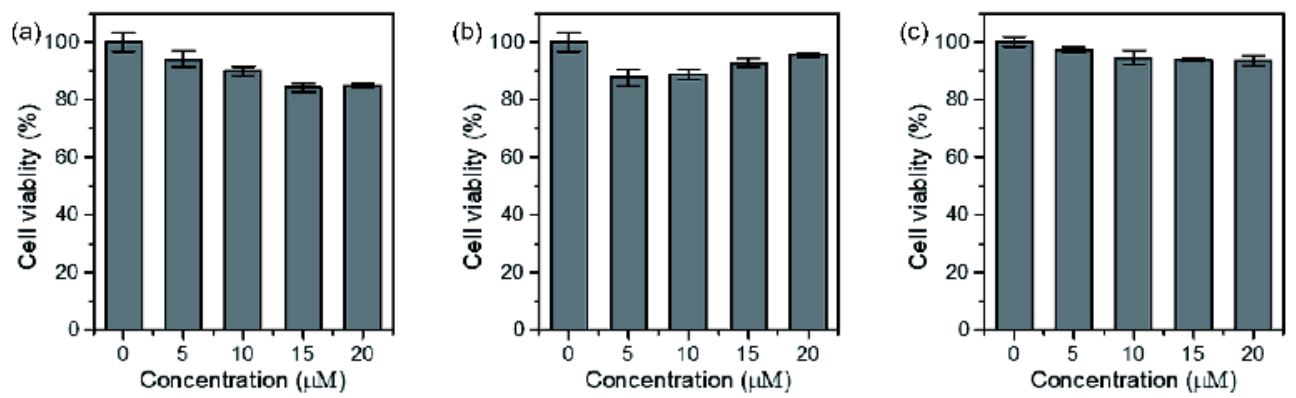

Figure 6 Cytotoxicity of (a) DPPG-incubated cells, (b) DPPF-G-incubated cells and (c) DPPS-G-incubated cells for $24 \mathrm{~h}$.

excellent sensitivity and selectivity by using AIE mechanism. The increases of glyco-DPPs emission in NIR region with the addition of lectins were attributed to formation of dye aggregates induced by sugar-glycoprotein interactions, which were determined by DLS and SEM analyses. More importantly, compared with DPPG and DPPF-G, DPPS-G with more sugar groups exhibits higher water solubility, better biocompatibility, longer emission and more significant fluorescence changes in the presence of lectins, suggesting that it is more suitable for intracellular imaging. In fact, DPPS-G has the ability to target HepG2 cells with very low toxicity. These AIE probes are easy-to-construct, biospecific and economic, which provide a reliable and widely applicable strategy for sensing both intercellular sugar-receptor interactions and targeted cancer cells. It is expected that this assay could form a generic platform for advanced molecular sensing with a high promise in practical applications.

Acknowledgements This work was supported by the National Natural Science Foundation of China (21772040, 21421004, 21372082, 21572062), the Fundamental Research Funds for the Central Universities (222201717003), the Programme of Introducing Talents of Discipline to Universities (B16017), a Visiting Program at NUS of China Scholarship Council (CSC), the Singapore Ministry of Education (R279-000-391-112), Singapore NRF Investigatorship (R279-000-444-281) and the National University of Singapore (R279-000-482-133).

Conflict of interest The authors declare that they have no conflict of interest.

Supporting information The supporting information is available online at http://chem.scichina.com and http://link.springer.com/journal/11426. The supporting materials are published as submitted, without typesetting or editing. The responsibility for scientific accuracy and content remains entirely with the authors.

1 Zeng X, Andrade CAS, Oliveira MDL, Sun XL. Anal Bioanal Chem, 2012, 402: 3161-3176

2 Wang KR, An HW, Rong RX, Cao ZR, Li XL. Biosens Bioelectron, 2014, 58: 27-32

3 Xue C, Jog SP, Murthy P, Liu H. Biomacromolecules, 2006, 7: 24702474

4 Li Z, Deng SS, Zang Y, Gu Z, He XP, Chen GR, Chen K, James TD, Li J, Long YT. Sci Rep, 2013, 3: 2293-2299

5 Jain K, Kesharwani P, Gupta U, Jain NK. Biomaterials, 2012, 33:
4166-4186

6 Liu FT, Rabinovich GA. Nat Rev Cancer, 2005, 5: 29-41

7 Zhang HL, Wei XL, Zang Y, Cao JY, Liu S, He XP, Chen Q, Long YT, Li J, Chen GR, Chen K. Adv Mater, 2013, 25: 4097-4101

8 Sansone F, Casnati A. Chem Soc Rev, 2013, 42: 4623

9 Gorityala BK, Lu Z, Leow ML, Ma J, Liu XW. J Am Chem Soc, 2012, 134: $15229-15232$

10 Martín Rodríguez E, Bogdan N, Capobianco JA, Orlandi S, Cavazzini M, Scalera C, Quici S. Dalton Trans, 2013, 42: 9453

11 Mei J, Leung NLC, Kwok RTK, Lam JWY, Tang BZ. Chem Rev, 2015, 115: 11718-11940

12 Zhu Q, Zhang Y, Nie H, Zhao Z, Liu S, Wong KS, Tang BZ. Chem Sci, 2015, 6: 4690-4697

13 Zhang CJ, Feng G, Xu S, Zhu Z, Lu X, Wu J, Liu B. Angew Chem Int $E d$, 2016, 55: 6192-6196

14 Chang ZF, Jing LM, Chen B, Zhang M, Cai X, Liu JJ, Ye YC, Lou X, Zhao Z, Liu B, Wang JL, Tang BZ. Chem Sci, 2016, 7: 4527-4536

15 Zhao E, Chen Y, Chen S, Deng H, Gui C, Leung CWT, Hong Y, Lam JWY, Tang BZ. Adv Mater, 2015, 27: 4931-4937

16 Yuan Y, Xu S, Cheng X, Cai X, Liu B. Angew Chem Int Ed, 2016, 55: 6457-6461

17 Yuan Y, Zhang CJ, Xu S, Liu B. Chem Sci, 2016, 7: 1862-1866

18 Yuan Y, Zhang CJ, Liu B. Angew Chem Int Ed, 2015, 54: 1141911423

19 Feng G, Yuan Y, Fang H, Zhang R, Xing B, Zhang G, Zhang D, Liu B. Chem Commun, 2015, 51: 12490-12493

20 Zhao N, Lam JWY, Sung HHY, Su HM, Williams ID, Wong KS, Tang BZ. Chem Eur J, 2014, 20: 133-138

21 Sanji T, Shiraishi K, Nakamura M, Tanaka M. Chem Asian J, 2010, 5: 817-824

22 Wang JX, Chen Q, Bian N, Yang F, Sun J, Qi AD, Yan CG, Han BH. Org Biomol Chem, 2011, 9: 2219-2226

23 Purc A, Sobczyk K, Sakagami Y, Ando A, Kamada K, Gryko DT. J Mater Chem C, 2015, 3: 742-749

24 Gao Y, Feng G, Jiang T, Goh C, Ng L, Liu B, Li B, Yang L, Hua J, Tian H. Adv Funct Mater, 2015, 25: 2857-2866

25 Zhang X, Hang Y, Qu W, Yan Y, Zhao P, Hua J. RSC Adv, 2016, 6: 20014-20020

26 Qu W, Yang L, Hang Y, Zhang X, Qu Y, Hua J. Sens Actuat B-Chem, 2015, 211: 275-282

27 Qu Y, Wu Y, Gao Y, Qu S, Yang L, Hua J. Sens Actuat B-Chem, 2014, 197: 13-19

28 Huang S, Liu S, Wang K, Yang C, Luo Y, Zhang Y, Cao B, Kang Y, Wang M. Nanoscale, 2015, 7: 889-895

29 Aigner D, Ungerböck B, Mayr T, Saf R, Klimant I, Borisov SM. $J$ Mater Chem C, 2013, 1: 5685-5693

30 Shen XY, Wang YJ, Zhang H, Qin A, Sun JZ, Tang BZ. Chem Commun, 2014, 50: 8747-8750

31 Wang L, Yang L, Cao D. Sens Actuat B-Chem, 2015, 221: 155-166

32 Hang Y, Wang J, Jiang T, Lu N, Hua J. Anal Chem, 2016, 88: 16961703

33 Jiang T, Li D, Hang Y, Gao Y, Zhang H, Zhao X, Li X, Li B, Qian J, 
Hua J. Dyes Pigments, 2016, 133: 201-213

34 Hang Y, He XP, Yang L, Hua J. Biosens Bioelectron, 2015, 65: 420426

35 Lai CH, Lin CY, Wu HT, Chan HS, Chuang YJ, Chen CT, Lin CC. Adv Funct Mater, 2010, 20: 3948-3958

36 Lai $\mathrm{CH}$, Chang TC, Chuang YJ, Tzou DL, Lin CC. Bioconjugate Chem, 2013, 24: 1698-1709

37 Maniam S, Holmes AB, Leeke GA, Bilic A, Collis GE. Org Lett,
2015, 17: 4022-4025

38 Zhang F, Jiang KJ, Huang JH, Yu CC, Li SG, Chen MG, Yang LM, Song YL. J Mater Chem A, 2013, 1: 4858-4863

39 He F, Liu L, Li L. Adv Funct Mater, 2011, 21: 3143-3149

40 Hasegawa T, Numata M, Okumura S, Kimura T, Sakurai K, Shinkai S. Org Biomol Chem, 2007, 5: 2404-2412

41 Tong H, Dong Y, Häussler M, Lam JWY, Sung HHY, Williams ID, Sun J, Tang BZ. Chem Commun, 2006, 127: 1133-1135 